\title{
Os Personagens da Família no Jogo Jurídico: Uma leitura sobre os processos judiciais em direito de família
}

\author{
Hélio Cardoso de Miranda Júnior * \\ Pontifícia Universidade Católica de Minas Gerais, Belo Horizonte MG, Brasil
}

\begin{abstract}
RESUMO
Este artigo procura demonstrar que os processos judiciais em Direito de Família são construídos com o uso de imagens/personagens para sustentar as argumentações dos advogados. Por meio da análise de petições e contestações dos processos judiciais de dois tipos de ações judiciais muito comuns, verificou-se o jogo de repetição dos argumentos em torno de imagens culturalmente relacionadas a concepções morais e ideológicas sobre a família e seus personagens, que se sobrepõem às discussões mais importantes a respeito das crianças ou adolescentes envolvidos nos conflitos familiares. Concluise que o modelo vigente não facilita a resolução de conflitos em família e pode ter consequências permanentes na maneira como se dão as relações familiares normatizadas pela instância judicial.
\end{abstract}

Palavras-chave: relações familiares, processos legais, justiça.

\section{ABSTRACT \\ The Family Characters in the Law Game: A reading of the lawsuits in the family law court}

This article aims to show that the lawsuits in the family court are built with the use of characters to support the lawyers' arguments. It uses as material petitions and lawsuit countercharges of two very common types of lawsuits. The analysis of the material enabled to check the repetition of arguments around images culturally related to moral and ideological concepts about the family that overlap the most important discussions about the children and adolescents involved. The same way it structures itself, the adversarial model does not facilitate the resolution of family conflicts and it can have permanent consequences in the way the familial relationships standardized by court happen.

Keywords: family relationships; lawsuits; justice.

A forma de composição do processo judicial em Direito de Família pode favorecer o litígio e dificultar a tomada de decisão judicial em função de características próprias ao jogo jurídico? Esta é a questão que nos guia neste texto. Se a resposta for afirmativa, tal jogo, na estrutura que possui hoje, não favorecerá a manutenção dos laços familiares em relações de respeito mútuo em famílias que passaram por um processo litigioso de modificação de sua composição ou organização.

Compor um processo judicial para provocar a instituição judiciária implica construir argumentos que favoreçam o convencimento do julgador sobre a causa demandada. Em Direito de Família, tais argumentos comumente fazem referências a valores culturais rela- tivos a imagens e a ideias fundamentais em nossa sociedade, como as de paternidade, maternidade, fraternidade, filiação, conjugalidade, etc. Ao fazer uso destas importantes imagens, atravessadas por determinantes históricos, versões e interpretações, os operadores do direito, muitas vezes sem estarem atentos a isso, colaboram ora na manutenção, ora na transformação de valores culturais por meio de um entrelaçamento discursivo da linguagem jurídica e a exaltação ou a crítica a imagens e personagens sociais com características supostamente intrínsecas, naturais.

No jogo estabelecido a partir das posições de autor e réu, ou requerente e requerido, tais imagens são manipuladas para afetar a atuação do representante do

* Endereço para correspondência: Hélio Cardoso de Miranda Júnior - mirandahelio@yahoo.com.br 
Ministério Público e a decisão do magistrado. O juiz necessita estar atento ao jogo e também às imagens para que possa produzir, nesta seara difícil, uma decisão que favoreça o sentimento do justo. Por isso, por diversas vezes, necessita também do auxílio dos técnicos das áreas social e psicológica.

O objetivo deste texto é apresentar uma abordagem dessas imagens, que se consubstanciam em personagens, realizada por meio de uma pesquisa. Para desenvolvermos este trabalho guiamo-nos pelas ideias de Balandier (1982) e Huizinga (1980) acerca do exercício do poder por meio das instituições jurídicas e a proposta de leitura da cena jurídica desenvolvida por Schritzmeyer (2001). Consideramos, também, as contribuições de Foucault $(1992,1996)$ sobre a noção de discurso e sobre o discurso jurídico.

\section{A CENA JURÍDICA}

Balandier (1982) entende que o exercício do poder na sociedade está ligado a formas de dramatização. Ele defende que o poder, para se manter, deve exercer certas teatralizações, que variam com o tempo e o contexto, porém sempre estão presentes. "Todo sistema de poder é um dispositivo destinado a produzir efeitos, entre os quais os que se comparam às ilusões criadas pelas ilusões do teatro" (Balandier, 1982, p. 6). De acordo com ele, há um parentesco entre as palavras "teoria" e "teatro", no duplo sentido grego do drama: agir e representar.

Segundo o autor, a manutenção da sociedade não depende somente da coerção de forças legitimadas, "mas também do conjunto de transfigurações de que é, ao mesmo tempo, o objeto e a realizadora" (Balandier, 1982, p. 21). Para ele, a manutenção da ordem depende da manutenção e reprodução de dramatizações para sustentar hierarquias, valores e crenças. $\mathrm{O}$ poder não consegue se manter somente pelo domínio brutal ou pela justificação racional. Ele se realiza e se conserva "pela transposição, pela produção de imagens, pela manipulação de símbolos e sua organização em um quadro cerimonial" (Balandier, 1982, p. 7).

Para Balandier, esta ideia está presente de forma explícita desde Maquiavel: o grande ator político comanda o real através da manipulação do imaginário, do jogo de imagens via espetáculo, que em nossa sociedade conta com o ingrediente importante da mídia e da valorização da técnica. Apesar de laicizados, os poderes modernos não eliminam os investimentos míticos necessários a seu funcionamento, apenas os encobrem, fazendo com que o exercício do poder tenha mais aparência de ordem técnica que simbólica.

Não cabe aqui uma exposição detalhada das ideias de Balandier, o que implicaria discutir, por exemplo, suas conclusões sobre a ordem e a desordem. Vamos nos restringir àquilo que pode ser útil na leitura dos processos judiciais das Varas de Família, local onde tramitam os processos judiciais em Direito de Família.

O outro autor de referência, Huizinga (1980), defende, em texto de 1936, que o jogo é elemento central na cultura, é forma "significante" e possui uma função social. Para ele, o direito e a justiça também compõem campos de jogo. Ele destaca as culturas nas quais os julgamentos se dão por processos muito distintos dos nossos, como os jogos de azar, as competições ou batalhas verbais (por exemplo, o torneio de insultos). Ele cita também aquelas em que esteve presente a ideia de decisão por oráculos ou pelo juízo divino ou mesmo pela sorte, nas quais explicitou-se mais claramente o caráter agonístico (e lúdico) do ganhar ou perder, aquém ou além da questão éticojurídica do bem e do mal. Para Huizinga, somente quando o estoicismo se tornou proeminente, surgiram os esforços para libertar a eloquência jurídica do caráter lúdico e purificá-la de acordo com os severos padrões de verdade e dignidade professados pelos estoicos.

Destaquemos, deste autor, sua referência ao processo do direito como uma competição, o que implica luta e representação de alguma coisa dentro de certos limites espaciais e de certas regras. Para nosso objetivo aqui, não é preciso considerar outras características que ele afirma pertencerem ao jogo como elemento da cultura (a vontade livre, a atividade externa à vida habitual e desligada dos interesses materiais, etc.).

Os dois autores citados foram utilizados por Schritzmeyer (2001) em sua leitura sobre o Tribunal do Júri, a parte mais conhecida da instituição judiciária e que se relaciona ao tratamento dos crimes contra a vida. Esta autora defende que o Júri pode ser compreendido como uma encenação que visa a controlar a legitimidade do poder de matar. Legitimidade esta que depende da forma como se narra a morte ocorrida e se descrevem os personagens envolvidos. Para ela, "a maior parte das narrativas de promotores e defensores do Júri está baseada num discurso de caráter dramático-sociológico" (Schritzmeyer, 2001, p. 112), pois embasado numa lógica classificatória e analítica sobre 
a organização e o funcionamento da vida social. Tais narrativas, que utilizam linguagem baseada em estereótipos e fazem dos réus, vítimas e testemunhas espécies de personagens reveladores, se tornam ainda mais fortes devido à forma de expressão utilizada e aos sentimentos que procuram evocar. Por vezes, os acusadores e defensores utilizam valores do senso comum para as suas argumentações num certo tipo de sociologia selvagem (termo apropriado da referência freudiana à "psicanálise selvagem"), transformando as expressões técnico-jurídicas com a força das expressões dramático-simbólicas.

Desta forma, fatos e ações que são banais no mundo cotidiano podem adquirir significados especiais quando representados nos plenários do Júri, situação na qual a diversidade humana é, geralmente, classificada e julgada a partir de certos sinais individuais que são interpretados como reveladores de características das relações humanas. Colocadas na boca dos técnicos (advogados), tais classificações ganham um status pseudotécnico-científico. Uma decorrência dessa encenação - produção de imagens, manipulação de símbolos e sua organização num quadro cerimonial - é a criação, naquele cenário, de "melodramas que, em alguma medida dizem respeito a - e fazem sentido para - todos" (Schritzmeyer, 2001, p. 120). Nestes melodramas, os atores sociais são remodelados para representarem não necessariamente o que são, mas o que deveriam ser em função do que deles supostamente esperam o Estado e a sociedade.

A narrativa melodramática no Tribunal do Júri gira em torno de um ou mais valores cuja universalidade está sendo testada e reeditada. Os argumentos levantados tencionam convencer a instância julgadora de que um valor social básico foi desrespeitado e deve haver uma redenção. De certa forma, no Júri é encenada uma etiqueta da vida social.

\section{OBJETIVO E MÉTODO}

A intenção de nossa pesquisa foi aplicar a mesma forma de leitura utilizada por Schritzmeyer aos processos em Vara de Família, para neles destacar a construção narrativa de personagens em meio ao jogo jurídico. Para isto, buscamos encontrar elementos da narrativa sobre os personagens e suas relações.

Existem poucas pesquisas que se aproximam desta perspectiva, mas não foi encontrada nenhuma, na pesquisa bibliográfica realizada, que utilizasse o mesmo material, o mesmo campo de estudos ou que seguisse a mesma orientação metodológica.

Para analisar o material coletado, utilizamos a metodologia de análise do discurso de Foucault, conforme se explicitará na sequência após indicarmos agora algumas outras pesquisas que se aproximam de nossa perspectiva.

Uma delas é a de Érika Reis (2009). Esta autora analisou, por meio da análise de discurso foucaultiana, as falas de pais e mães ligados a processos judiciais em Direito de Família. Segundo ela, nas Varas de Família homens e mulheres são capturados na interface entre o discurso jurídico e outros discursos de forma que se alienam em identidades de gênero presas a normas essencialistas,

[...] cujo poder e força de convencimento se associam à veiculação incessante de uma série de mitos referentes às expectativas com relação aos gêneros e às instituições da maternidade e da paternidade, que historicamente têm demarcado lugares sociais, psicológicos e afetivos para os indivíduos. (Reis, 2009, p. 98)

Reis (2009) afirma que há uma 'política representacional' baseada na imposição de categorias de identidade, o que leva os indivíduos a serem sujeitos de determinados enunciados e não de outros. Um dado, a título de exemplo, que ela colheu em seus resultados e que é o mais comum na prática das Varas de Família apesar das mudanças sociais e históricas - é a identidade da 'mãe cuidadora' como necessariamente a principal responsável pela casa e pelos filhos, já que os homens não têm competência para isso.

Além disso, a autora afirma que as estratégias usadas pelos indivíduos nas disputas jurídicas utilizam tais discursos identitários. Acrescenta ela que há comumente um uso do discurso sobre o risco - para a saúde, o bem-estar ou o desenvolvimento saudável e adequado - de as crianças permanecerem com o oponente, como guardião, em função de suas condutas e atitudes. A categoria de risco faz referência ao conceito de biopoder de Foucault.

Outra pesquisa que utiliza a ideia de que o discurso jurídico constrói personagens implicados em determinadas cenas, havendo lugares específicos a serem ocupados e papéis a serem desempenhados, foi feita por Cerruti (2007). Esta autora desenvolveu sua pesquisa a partir de atendimentos realizados a mulheres 
vítimas de violência e sua ênfase recaiu sobre o lugar - ou o papel - de vítima que o discurso jurídico confere a estas mulheres. Tal lugar deriva de uma noção de proteção que, por meio de argumentos adversariais, opõe vítima e agressor. Com o cuidado de não desmerecer o ganho histórico do direito das mulheres, Cerruti (2007) enfatiza alguns dos efeitos deste discurso polarizado, como, por exemplo, a rememoração incessante da cena que fixa o sujeito na posição de vitimizado frente ao Direito (às instituições jurídicas) que, como agente (Outro), deve garantir a este sujeito uma reparação ou o retorno de seu bem-estar, independentemente da singularidade envolvida em cada caso. Para ela, a uniformização desse discurso tem um caráter alienante para cada sujeito envolvido.

Mais um exemplo que se aproxima de nossa perspectiva é a de Moreira \& Toneli (2014), que investigaram o uso da noção discursiva de paternidade em sua relação com a criminalidade nas jurisprudências de Tribunais de Justiça. As autoras concluíram que o discurso jurídico atual tende a estabelecer uma relação entre o comportamento criminoso e família, no sentido de que a família ajuda a constituir uma personalidade que tende ao crime. O papel do pai é destacado nesta relação, sendo que, por vezes, de forma contrária, a imagem de 'ser pai' ou 'pai de família' também pode ser considerada um ponto positivo na avaliação de uma pessoa.

As três autoras mencionadas utilizaram a fala das pessoas envolvidas nos respectivos processos jurídicos, sendo que Moreira \& Toneli (2014) usaram apenas as jurisprudências acessadas por meio da internet e Schritzmeyer (2001), especificamente, utilizou também um diário de campo. Nossa pesquisa, diferentemente, utiliza os próprios papéis que compõem os processos judiciais de ações de guarda de menor e também os de modificação de guarda de menor, conforme melhor definido abaixo.

A presente pesquisa compôs, de forma suplementar, a pesquisa de doutorado do mesmo autor, que procurou investigar a possibilidade de intervenção nos conflitos de família encaminhados para o trabalho técnico de psicólogos e assistentes sociais em um Tribunal de Justiça. Este foi um fator que facilitou o acesso ao material. A escolha dos dois tipos de ações judiciais citadas acima se deu em função de que tais ações compõem a maior parte das ações recebidas pelos técnicos. Como constataram Rodrigues, Couto \& Hungria (2005), 42,67\% dos processos encaminhados para uma das equipes multidisciplinares na cidade de São Paulo pertenciam aos tipos de ações citados acima. O material de pesquisa estava relacionado aos processos nos quais se demandou o trabalho da psicologia e da assistência social em função da facilidade de acesso já mencionada.

Além disso, nestas ações, em geral os litígios familiares estão mais explícitos, o que, a princípio, favorece a construção discursiva dos personagens litigantes. Isto é corroborado por outros autores, como Shine (2002), por exemplo. Evidentemente, deixamos de considerar outros tipos de ações judiciais nas quais a guarda das crianças e adolescentes estava em questão, mas cujo nome da ação não se enquadrava nos citados acima (como, por exemplo, ações de medida cautelar e divórcio litigioso).

Durante os três meses em que foi realizada a pesquisa, os psicólogos da equipe daquele Tribunal receberam um total de 340 processos, sendo 125 nas ações acima citadas. Foram escolhidos, aleatoriamente, quatro psicólogos - de uma equipe composta por 20 técnicos à época - no primeiro mês, três no segundo e dois no terceiro para que os processos por eles recebidos fossem consultados para a coleta de informações necessárias à pesquisa. Ao todo, foram utilizados 19 processos $(15,2 \%$ do total recebido pela equipe nestes períodos em ações dos tipos citados). Em 4 deles não havia litígio.

Nos processos utilizados, limitamo-nos à leitura da petição inicial e da contestação, quando havia. Isto porque, na fase postulatória do processo, fase da propositura da ação, a petição inicial é o veículo de manifestação formal da demanda, ato pelo qual alguém pede ao Estado a prestação jurisdicional. Entre seus requisitos está a descrição escrita dos fatos e dos fundamentos jurídicos do pedido. Segundo o princípio da substanciação, tal descrição deve indicar o direito subjetivo que se pretende exercitar e apontar o fato de onde ele provém e, também, o nexo jurídico capaz de justificar o pedido. De acordo com Theodoro Júnior (2005), a petição inicial é a chave que abre o processo, pois revela e formata a pretensão do autor, sendo, assim, a forma de exercer o direito de ação. Ainda nesta fase, a defesa do réu pode se dar no plano da relação processual (conteúdo apenas formal) e no plano do direito material (cujo conteúdo é o mérito da 
causa, ou seja, o fato jurídico arguido pelo autor). Tal defesa é chamada contestação que é, portanto, "o instrumento processual utilizado pelo réu para opor-se, formal ou materialmente, à pretensão deduzida em juízo pelo autor" (Theodoro Júnior, 2005, p. 350). Interessante ressaltar que a contestação deve abarcar toda a matéria da petição inicial, não sendo possível abordar em fases posteriores do processo matéria presente na petição inicial e não arguida na contestação.

Antes de prosseguir, devemos mencionar que a resposta do réu pode ser a contestação, a exceção ou a reconvenção. Escolhemos apenas as contestações, que é a resposta mais comum e porque nelas podemos perceber como se estabelece o jogo de ataque e defe$\mathrm{sa} /$ contra-ataque (terminologia explicitamente empregada no direito processual) cujos componentes / oponentes são as partes processuais designadas como autor e réu. No caso das Varas de Família em que tramitavam esses processos adotavam-se os termos requerente e requerido.

Cabe ressaltar que, dentre os processos utilizados, quatro não possuíam contestação e nenhum teve como resposta do réu a reconvenção.

Foucault propõe que em toda sociedade, "a produção do discurso é ao mesmo tempo controlada, selecionada, organizada e redistribuída por certo número de procedimentos que têm por função conjurar seus poderes e perigos, dominar seu acontecimento aleatório, esquivar sua pesada e temível materialidade" (Foucault, 1996, p. 8-9). Neste sentido, as práticas socioculturais delimitam e circunscrevem os tipos de experiência possível (Foucault, 1996).

O objetivo destes procedimentos é apresentar o discurso como verdade acabada, como uma unidade não aleatória (aleatório que Foucault coloca sob a rubrica da noção de acontecimento). Para esta análise, partimos da compreensão de que o discurso não é uma criação pura, vários fatores concorrem para o seu aparecimento. Assim, o discurso não possui caráter meramente instrumental, nem somente de correspondência simples com a realidade. Ademais, não é uma unidade isolada, mas encadeia-se numa série histórica, o que significa que o discurso não é apenas representação do mundo, mas significação e constituição deste mundo, sendo fruto de um processo de saber-poder que se repete e se recria. Por fim, não importa tanto o que significa o discurso, mas quais as condições que permitiram seu aparecimento.

Neste sentido, a proposta foucaultiana que privilegiamos é a de buscar as condições de existência do discurso, o que quer dizer buscar a posição que pode e deve ser ocupada pelo indivíduo para que ele seja o sujeito de determinado discurso (Foucault,1987). Assim, seguindo a elaboração de Reis (2009), buscamos nos discursos um campo de regularidade para as diversas posições de subjetividade.

Pelo exposto, podemos afirmar que a presente pesquisa contribui para ampliar a compreensão dos jogos adversariais típicos dos conflitos familiares judicializados. Isso auxilia a colocar em questão a forma de tratamento destes conflitos pelo Poder Judiciário e a refletir sobre alternativas a este tratamento.

\section{RESULTADOS}

O jogo dos argumentos, nas redações dos advogados, baseia-se na narrativa sobre as pessoas / personagens envolvidos nas questões jurídicas de família e suas vidas (características pessoais, intenções, fatos, etc.). De forma genérica, os personagens desse jogo foram reunidos em dois grupos: os adultos e as crianças / adolescentes. Optamos por caracterizar o adulto sem nos atermos ao gênero, à idade ou a outras variáveis. Também a criança e o adolescente serão caracterizados de forma genérica. A correlação de outras variáveis para essa caracterização poderá ser tema de futuras pesquisas.

De forma esquemática, a narrativa sobre o adulto é composta por quatro campos distintos: as suas características pessoais; as condições (materiais, morais, afetivas, psicológicas, espirituais, religiosas) que possui e que oferece à criança; e o interesse que ele tem ou manifesta em relação à criança. Estes três campos, e principalmente o das condições e o do interesse, vinculam-se ao quarto campo, o da assistência que deve ser dada à criança, relacionada às obrigações e aos deveres dos adultos e à garantia dos direitos das crianças.

Evidentemente, o destaque desses temas já faz parte da leitura do material realizada pelo autor. Assim, tanto os temas quanto as outras categorias citadas a seguir abaixo foram criadas no processo de interação do pesquisador com o texto no intuito de organizar o material segundo suas regularidades e, com isto, poder 
auxiliar na compreensão da dinâmica e da lógica processual em direito de família. Porém não devem ser tomadas como padrão para qualquer outra leitura realizada com o mesmo objetivo, principalmente porque possuem limitações que incitam outras pesquisas.

A criança aparece, basicamente, vinculada à ideia da necessidade de proteção, sendo as categorias em torno de seu personagem submetidas a este crivo.

Daqui em diante, todas as palavras em itálico foram retiradas do próprio texto das petições e das contestações utilizadas. Registramos aqui as citações mais comuns, representativas do discurso mais presente, e também as mais incomuns. Os colchetes indicam as palavras que se relacionam ao contexto original da frase e foram acrescentados para que o sentido se tornasse compreensível.

\section{1 - Os adultos}

1.1 - Com relação ao primeiro campo citado, o das características pessoais dos adultos, destacam-se quatro itens importantes: o trabalho do adulto, sua idoneidade, a sua saúde e a estabilidade de suas relações. Este campo pode ser sintetizado em uma noção utilizada em um dos processos e que possui atualmente alto valor cultural: a competência. Em um caso, por exemplo, o pai argumentava que a mãe não conseguiu manter o controle sobre os filhos $e$ os entregou a ele.

1.1.1 - Com relação ao trabalho, percebe-se uma ênfase na imagem do indivíduo trabalhador, relacionada ao esforço do trabalho, à estabilidade no emprego, aos recursos provenientes da atividade laboral e à adaptação social. Geralmente, são características valorizadas positivamente (ser aposentado, mas ainda trabalhar / é professora, tendo realizado o mestrado / trabalha há mais de dez anos no mesmo local / tem profissão fixa) que se contrapõem àquelas com valor negativo (não ter trabalho fixo / não permanecer em nenhum emprego por mais de um ano). Há argumentos que deixam implícita a imagem de que a mulher não deveria trabalhar para que pudesse cuidar dos filhos (por exemplo, foi obrigada a trabalhar, pois o requerido não ajudava na criação do filho).

O trabalho se torna um problema, como argumento, quando se relaciona à dificuldade de assistência à criança, tema que será abordado adiante.

1.1.2 - A categoria da idoneidade, num sentido amplo desta noção, aparece em afirmativas como: é idôneo / tem conduta ilibada / honestidade indiscutível /consciente da responsabilidade / boa mãe, bom caráter moral / não possui vícios / nada os desabona / tem comportamento exemplar lé admirada / goza de prestígio e estima na comunidade.

Tais assertivas contrastam com afirmativas contrárias, de maneira simplista: ser desleixado / não ser bom exemplo de comportamento / viver de forma desequilibrada / pessoa em quem não se tem a menor confiança / ser pessoa perigosa, como demonstram as ameaças que fez / estar sempre embriagado / interferir no ambiente de trabalho [da outra pessoa].

Geralmente, esses argumentos não estão acompanhados de justificativas. São apenas afirmativas simples, baseadas em imagens e discursos compartilhados, porém sem fundamento sólido. O conteúdo moral presente nesses argumentos é bastante claro. Em um dos processos, por exemplo, o pai enfatiza que a mãe tinha filhos de pais diferentes e, portanto, não poderia proporcionar ambiente adequado de criação para a criança.

Destaca-se o uso de argumentos deste tipo quando se quer demonstrar que o outro manipula o jogo judiciário em benefício próprio por meio de um jogo intersubjetivo (exemplo: o comparecimento espontâneo à delegacia teve o intuito de denegrir a imagem do defendente).

Destacamos também um argumento que fazia uma afirmação de alto apelo emocional para indicar, segundo o advogado, a dificuldade de relacionamento social de uma pessoa a partir da qualidade de sua relação com sua própria mãe, afirmando que tal relacionamento era desarmonioso. Isso deixa implícita a ideia de que a relação com a mãe deve ser sempre harmoniosa. Em um outro, a mãe teria feito uma representação contra a filha, suposto sinal de que tal filha teria mau comportamento.

1.1.3 - A saúde é invocada para argumentar, também de maneira simplista, sobre as condições para o exercício da guarda (ser jovem e saudável) ou para argumentar que o outro não as possui, caso em que são elencadas razões médicas para fundamentar os argumentos: o pai teve AVC com sequelas / pessoas idosas que não possuem tempo e disposição necessária para a devida criação e educação.

1.2 - No campo das condições dos adultos, dois itens se destacam: o ambiente que circunda a criança 
e o tempo que também indica, aqui, a estabilidade das relações.

1.2.1 - O ambiente é, por vezes, citado afirmativamente como ambiente saudável ou ambiente adequado ou equilibrado, sem que se preocupem os advogados em sustentar tal afirmativa com fatos. Porém, quando o fazem, por vezes utilizam expressões pouco concretas, mas de alto apelo cultural: ambiente de carinho, amor e boa educação / lar estruturado / ambiente familiar adequado ao desenvolvimento, cercado de alegria e afetividade / a insubstituível companhia materna.

Outras vezes, citam-se características mais objetivas, como as condições físicas de uma residência (número de cômodos de uma casa; número de móveis: residência física / apartamento próprio com cinco cômodos la casa é um ambiente organizado e com condições adequadas de moradia) mas que, em si, também não indicam claramente o valor dos argumentos.

No ambiente também aparece aquilo que é considerado inadequado: levar filhos para bares e botecos / [fazer os filhos] presenciarem estados de embriaguez I [receber na sua casa] pessoas estranhas e do sexo oposto que ali pernoitam. Comumente, o ambiente 'inadequado' está relacionado com questões ou comportamentos sexuais.

É curiosa a citação, especificamente, da cama, principalmente para uma correlação, nem sempre explicitada, entre o fato de a criança não possuir uma cama própria e a inadequação de seu pernoite. $\mathrm{O}$ argumento a seguir mostra como deve ser organizado o ambiente para que a criança durma: o filho tem um quarto só pra ele para ter referencial de espaço e de família.

Geralmente os argumentos procuram enfatizar o lado moral da inadequação, mas em um dos processos se dizia que a criança sofrera várias quedas por dividir a cama com sua mãe. Em outro foi afirmado que $a$ casa possui poucos quartos e o filho dorme na cama dos avós paternos.

1.2.2 - Os argumentos dos advogados também constroem uma relação entre o adulto e a criança, pautada no tempo, para demonstrar a existência ou o estabelecimento de afeição/afetividade entre ambos: está ao lado desde o nascimento do mesmo / sempre nutriu amor de filho, nunca perdeu contato / amor $e$ dedicação desde o nascimento / passado mais de um ano de convivência.
Quanto mais tempo e mais convivência, mais afetividade, no sentido de laço de afeição ou laço amoroso - é o que está implícito nos argumentos. Há um argumento curioso que afirma uma data para o início da convivência entre adulto e criança para mostrar que a criança não convive há tanto tempo com o adulto e, portanto, não teria desenvolvido a afeição e a adaptação afirmadas pela outra parte processual.

O item tempo também aparece como fator relativo à estabilidade das relações matrimoniais, o que seria, de acordo com os argumentos, um sinal positivo: $c a-$ sados há cinco anos / tem vida harmoniosa / matrimônio desde 1973 / com quem vive há 9 anos / com quem possui um filho com 5 anos de idade.

1.3 - O campo do interesse é relacionado à vontade da pessoa. É uma categoria que possui a particularidade de ser, muitas vezes, deduzida das atitudes e das decisões dos adultos e relacionada à sua disponibilidade para cuidar da criança (assumiu a paternidade sem nenhuma pressão / sempre auxiliou o pai em relação aos cuidados à filha / deixava a criança na casa dos avós paternos porque precisava trabalhar, inclusive mudou para perto da casa destes avós / vivendo em função dos filhos). Pode estar relacionada positivamente ou negativamente também a outras condições (não trabalha, ficando todo o tempo disponível para os filhos, podendo ajudar e cuidar melhor / jamais se preocupou com esta criança, mesmo porque tem outros filhos).

Sua correlação com o campo da assistência é importante por causa da via lógica linear entre dar assistência e, portanto, demonstrar interesse ou vice-versa. Muitas vezes o interesse é indicado pelo fato de a pessoa ter registrado a criança (em geral, o pai, apesar das dúvidas sobre a paternidade). Em alguns casos, a falta de interesse do adulto é relacionada à assistência (que será tratada em item específico) e ao tempo: não ser presente / não pagar pensão / não visitar a criança há muito tempo / manter pouco contato com a filha / não se interessar pela rotina ou pelo ambiente no qual o filho vive / saía de casa e se ausentava por longos períodos / desinteressar-se pelo filho após iniciar novo relacionamento amoroso / pai ausente em face do trabalho ou no bar ou com companheiros.

Como trata de uma questão subjetiva, o interesse do adulto é categoria muito ambivalente. Por exemplo, a concordância do genitor da criança em entregar 
a guarda ao outro genitor ou a terceiros pode indicar seu desinteresse pelo filho, nos processos em que há litígio, ou um maior interesse pelo bem-estar da criança, nos processos em que não há litígio, como se nestes últimos o responsável legal reconhecesse que o outro adulto poderá cuidar melhor do filho. Por vezes, se utiliza a ideia de real interesse para contra-argumentar um suposto falso interesse da outra parte: vem se utilizando dos filhos para impossibilitar a venda do imóvel / deseja apenas a pensão alimentícia.

Para demonstrar interesse genuíno pela criança, em alguns casos os adultos afirmam que ela não possui bens.

O interesse do adulto também pode ser confrontado ao direito ou ao interesse da criança. Neste tipo de narrativa, o interesse do adulto seria pessoal (ganhar a causa, adquirir ou usufruir vantagem pessoal objetiva ou afetiva, etc.) e se exerceria contra o interesse maior da criança, como: impedia os contatos com o filho / manipular a vontade do menor. Evidentemente, tais argumentos são usados pelos advogados contra seus oponentes.

1.4 - A assistência é uma categoria associada a diversas dimensões práticas do cotidiano, muitas vezes contraposta à ideia de privação. Afirma-se muito a importância de dar/fornecer assistência à - ou atender às necessidades da - criança. $O$ contrário é indicado como abandono. Tal assistência é adjetivada de várias formas (moral, intelectual, física, mental, material, religiosa) e é invocada em nome do pleno desenvolvimento ou da garantia dos direitos da criança. Algumas vezes aparecem argumentos que apelam às relações afetivas (por exemplo, recebendo apoio $e$ carinho de seu pai / dar afeto e amor / [responsabilizar-se] pela inclusão social dos menores).

Em termos práticos, a assistência aparece relacionada, por exemplo, à pensão alimentícia. O não pagamento ou o seu valor insuficiente são tratados como sinais de falta de assistência material, o mesmo podendo ser afirmado do ato de recusar-se a recebê-la ou desinteressar-se por tal recebimento, ou ainda o seu desvio, pelo recebedor, para utilização particular em detrimento das crianças, o que pode levar os filhos a privações. Por outro lado, o pagamento regular parece indicar compromisso com a assistência.

Algumas vezes, a assistência é referida também aos benefícios que o adulto pode oferecer à criança em função de suas condições financeiras ou de trabalho, como a inserção da criança em plano de saúde ou vantagens escolares. Neste mesmo esteio, relaciona-se algumas condições do adulto a uma melhor assistência à criança, como ter residência fixa, trabalho estável ou contínuo, situação financeira favorável.

Outras vezes, a assistência se refere ao campo da saúde, via argumentos sobre adoecimento e higienização: [ela] é desleixada, os filhos estão sempre doentes e sujos / a criança está bem de saúde e feliz / [as crianças] têm saúde, não quedaram doentes nos últimos tempos e tomam banho todos os dias / não providenciou médico para o filho Inunca lhe eram cortados os cabelos / com constantes dores de cabeça, sem higiene adequada e sem assistência médica.

A capacidade para dar assistência à criança é, muitas vezes, confrontada com o trabalho do adulto, seja para indicar a incapacidade de uma assistência adequada (para trabalhar deixa a criança desacompanhada de conhecidos, em local estranho / [o fato de] ser músico e não poder cuidar da filha à noite / [trabalhar viajando por diversas cidades e daí] não ter residência fixa e não poder cuidar das crianças / devido ao seu horário de trabalho estava impossibilitada de cuidar das crianças) seja para indicar o esforço para dar assistência (para evitar que os filhos passem necessidade, ela trabalha / dedicar-se exclusivamente à família /trabalha pesado como diarista / apesar do trabalho fora, ela dispensa carinho materno necessário ao amparo psicológico [da criança].

$\mathrm{O}$ argumento que questiona a assistência e que é usado contra o oponente é o do abandono, muitas vezes relacionado também a não ter interesse ou a delegar responsabilidade a terceiros. Os argumentos de defesa de quem é acusado de abandono variam desde registrar a criança no seu nascimento, passam pelo pagamento da pensão regularmente e chegam até a questão da delegação de responsabilidade a terceiros com critério ou com boas intenções: contratou babá, [portanto] as crianças não estão abandonadas / deixou a criança com o pai e este a repassou para sua mãe / já que havia sido ameaçada e agredida pelo requerido, resolveu deixar o filho com os avós paternos, mas jamais o abandonou. Curiosamente, este último tipo de argumento é citado nos processos em que há litígio, sendo que, quando há consenso sobre a guarda não se fala em abandono, mas na entrega da criança para ser cuidada ou criada por outros. Assim, podemos ver como o abandono é categoria utilizada comumente quando é preciso construir uma imagem ruim de uma das partes processuais. 
1.4.1 - Um item de destaque no campo da assistência é o da educação. A educação se refere à escolarização e também ao "exemplo" que os adultos fornecem com suas atitudes e orientações às crianças. Destaca-se a preocupação com a escolarização, presente em muitos argumentos em diversas redações: estar matriculada / providenciar matrícula /procurar escola mais perto ou melhor / [procurar uma] boa formação educacional, [que não pode ser] em qualquer escola.

A insistência deste tipo de argumento é curiosa em função de seu oposto, quer dizer, a suposta inexistência de uma preocupação com a educação da criança pela parte contrária, argumento apenas implícito em algumas petições. Essa falta de preocupação com a educação significaria um ato de "negligência" nos termos do valor social atual da educação formal, cujo respaldo legal encontra-se no Estatuto da Criança e do Adolescente (ECA). Por vezes, cita-se a presença ou ausência do responsável nas reuniões escolares da criança como um signo de assistência ou de interesse.

Quando se trata da educação informal, quer dizer, o exemplo e a orientação esperado do adulto em relação à criança, os argumentos, por vezes, também não se ocupam de indicar fatos, resumindo-se a afirmativas simples como proporcionar exemplo de conduta moral e ilibada / educar com amor e dedicação. Nos argumentos em que a conduta do adulto é questionada no sentido do exemplo a ser dado, ela aparece relacionada a aspectos práticos, porém com destaque para o inverso, quer dizer, para as ações reprováveis: maltratar com agressões verbais e físicas / expor a situações de ambientes como bares / forçar ao trabalho [em detrimento da escola] / viver de forma desequilibrada, sem trabalho, com mais filhos e sem ter o que oferecer a eles.

Neste ponto surgem argumentos de cunho psicológico relativos às consequências dessas condutas: condutas que alteram os valores morais dos filhos / atitudes que vêm de encontro à boa formação moral $e$ psicológica, comprometendo, de morte, a formação da personalidade.

\section{2 - As crianças e adolescentes}

Não é incomum citar pouco as crianças e os adolescentes em termos diretos. Fala-se muito sobre eles indiretamente, abordando a assistência, o desenvolvimento, o ambiente e a educação. Tais ideias gravitam em torno da noção de proteção. Argumenta-se ainda sobre a adaptação da criança e sobre sua vontade.

A noção de proteção parece acompanhar quase todos os argumentos em relação às crianças e aos adolescentes. Não se fala diretamente de proteção, mas, em sintonia com o ECA, podemos asseverar que a proteção, de acordo com os argumentos encontrados, seja, fundamentalmente, dar assistência adequada. Esta assistência visa a permitir o desenvolvimento da criança, argumento muito utilizado: preocupar-se com o desenvolvimento / cuidado para desenvolver-se / ambiente adequado ao desenvolvimento / ter criação adequada e pleno desenvolvimento / trabalho bruto que impedia de estudar, brincar e se desenvolver considerando as peculiaridades da pessoa em desenvolvimento / estrutura familiar que se relaciona com uma estrutura psíquica adequada ao desenvolvimento.

Desenvolvimento que também pode aparecer como formação ou constituição pessoal: rotina adequada à formação de sua personalidade, caráter, hombridade / criar condições para que, no seu processo de constituição enquanto sujeito, possa constituir isso que chamaremos de estrutura familiar.

O destaque da noção de desenvolvimento nos argumentos faz eco à noção central do ECA de 'pessoa em desenvolvimento'. Noção que possui história político-social importante e cujas relações com o discurso psicológico, por exemplo, foram trabalhadas por Miranda Jr. (1999).

Questões sobre o ambiente a ser oferecido à criança também são referências comuns. Neste tópico podem se encontrar argumentos de cunho psicológico como, por exemplo: é inquestionável, em qualquer teoria psicológica sobre a estruturação psíquica da criança, o papel relevante da função familiar.

Cuidados relativos à saúde e à higiene (levar ao médico, vacinar, banhar, trocar roupas, etc.) são comumente invocados, sendo citado também o amparo psicológico, sem se explicitar a que se refere o termo. Utilizam-se documentos como exames para comprovar a boa saúde física.

A educação também é constantemente invocada como necessidade para a formação da criança. A escola e a família são os lugares institucionais privilegiados desta educação. O trabalho da criança, presente em apenas um dos processos, é confrontado com sua possibilidade de estudar em escola. Neste processo, uma das partes, para justificar o trabalho do filho na 
sua companhia, argumenta sobre características de sua profissão e acrescenta que o trabalho, além de afastar das más companhias, [forma a pessoa] honrada, com personalidade forte, definidora dos destinos. Acrescenta, depois, que o trabalho precoce forma o caráter, a hombridade, desde que sem excesso.

A escola é, sempre, item de destaque, sendo por vezes agente de produção de documentos para serem incluídos nos autos - como matrícula, frequência, declarações, etc. A frequência à escola é muito utilizada para indicar adequação com o que se espera das crianças e adolescentes na sociedade (frequentando regularmente as aulas / o menor tem um excelente aproveitamento escolar). As notas também entram neste raciocínio e são, assim, utilizadas para indicar a qualidade da assistência.

Muitas vezes há referência ao tratamento dado à criança em termos corretivos, na educação em casa. Em geral argumentos de ataque baseados na ideia de que a correção educativa de crianças e adolescentes não deve comportar agressão: estava sofrendo maustratos por parte do seu padrasto / [o adulto] com frequência batia-lhe com palmadas, cinta e toalha molhada / a criança sofria violência doméstica / sofre chantagens dele.

O ambiente, o tratamento em casa e a escola, ou a ausência dela, podem ser interligados na ideia de um risco a que a criança estaria sendo submetida, categoria pouco utilizada de forma direta neste material de pesquisa.

A adaptação da criança também é destacada como argumento contra ou a favor da companhia do adulto: está perfeitamente ajustada ao ambiente familiar / a criança não se adaptou à moradia na companhia da mãe / está adaptada [depois de três anos e quatro meses] / viviam felizes com sua mãe, como deve ser.

Percebe-se que o tempo também é fator relevante como sinal de adaptação ou de afeição da criança em relação ao adulto: desde os oito meses de idade / está com quatro anos e [já] estuda... / o menor sempre nutriu por este [pai] amor de filho / após um ano de convivência, tendo a criança cinco anos, guarda pela tia-avó grande afeição.

A vontade da criança também aparece como item importante, mas pouco utilizado nos casos analisados. Como categoria subjetiva, também é manipulada de forma ambivalente nos argumentos: atender à vontade da filha em se mudar / [a criança] está satisfeita e demonstrou interesse / [o adolescente] prefere o ambiente [pois] nasceu e se criou lá / [a criança] não quer mais morar com [a mãe].

Em apenas um processo havia um argumento sobre a criança estar privada de brincar. Em apenas um processo, também, se argumentava contra a separação de irmãos, que deve ser evitada, de acordo com o ECA, mas que em processos de família não é uma situação muito comum. Para mencionar um último dado curioso, em um dos processos argumentou-se que a vontade do 'menor', externada em documento assinado por ele, fora manipulada pela mãe.

\section{DISCUSSÃO}

Primeiramente, fica claro o efeito dramático a que se visa nesses argumentos, conforme também destacou Schritzmeyer (2001) em sua pesquisa sobre o Tribunal do Júri.

Podemos perceber como a linguagem utilizada nas petições e contestações dos processos judiciais de guarda e de modificação de guarda constroem personagens como base para muitos argumentos sobre o Direito de Família, tendo como apoio discursivo (e ideológico) a ideia central da proteção integral da criança e do adolescente. Tais personagens ficcionais projetam o ideal de um adulto equilibrado, estável na profissão e no relacionamento amoroso e com disponibilidade para cuidar das crianças. 'Cuidar' que se mostra um difícil conjunto de tarefas nas quais a necessidade de assistência à criança, por exemplo, é ponto pacífico, mas sua amplitude e qualidade sempre são pontos de discussão.

Os personagens adultos se definem principalmente pelas condições que oferecem às crianças, enquanto elas se definem pela assistência de que necessitam. A imagem do adulto ideal extraída na pesquisa é o de um indivíduo que trabalha e ao mesmo tempo tem disponibilidade para cuidar das crianças, fornecendo um ambiente adequado e acompanhando sua escolarização. Este último aspecto tem um apelo argumentativo bem extenso. A criança e o adolescente, por seu lado, aparecem como carentes (de cuidado, de acompanhamento) e com direito a receber o que o adulto deve oferecer.

Alguns outros aspectos, como o direito do adulto ou a vontade da criança parecem receber valor secun- 
dário, ao mesmo tempo em que são de fácil manipulação narrativa pelos advogados, quer dizer, quando a vontade da criança, por exemplo, se torna interessante para o advogado, ele a menciona como um valor primário a ser considerado.

Poderíamos caracterizar essas narrativas como melodramáticas. "O melodrama requer que o mal seja abatido - o que é uma ideia moral" (Balandier, 1982, p. 33). No melodrama o final é feliz e o acaso e a tristeza são visitantes indesejáveis.

Nos argumentos em Direito de Família, as pessoas e as vidas concretas ali inscritas e descritas são comparadas a uma ficção, a um ideal social. Neste sentido, ao agir - tramitar processos, sentenciar - o poder judiciário "devolve uma imagem idealizada desta sociedade e, portanto, [uma imagem] aceitável" (Balandier, 1982, p. 10). A concordância em torno dessa idealização se dá porque "é difícil reconhecer as mazelas não como desvios, mas como características do caminho principal” (Schritzmeyer, 2001, p. 122).

Schritzmeyer chega a afirmar, sobre o Tribunal do Júri, que o juiz e o promotor "ao julgar dramas aparentemente interindividuais, segundo valores aparentemente coletivos, [...] disfarçam - para si e para os outros - o caráter social dos dramas e o viés elitista e hierarquizado dos valores em que o sistema se pauta para julgá-los" (Schritzmeyer, 2001, p. 119). Não é possível afirmar com certeza o mesmo para o Direito de Família a partir apenas desta pesquisa, porém constata-se a importância que assume no processo judicial o uso de estereótipos e a manipulação das imagens no jogo discursivo de ataque, defesa e contra-ataque.

Destaca-se a impressão de óbvio que sentimos na leitura dos argumentos dos advogados, como se todos partilhássemos uma unanimidade em torno de certas noções relativas à família, às crianças e aos adolescentes. Tal unanimidade, em verdade, parece estar relacionada à normatização familiar, noção que podemos extrair de Foucault $(1992,1996)$ e Donzelot (1980). Tal normatização aparece implícita nessas figuras criadas para o jogo jurídico, com respaldo em valores ideológico-culturais. A produção de normas de conduta e de identidade coloniza, cada vez mais, a produção e o exercício do direito (Fonseca, 2002).

Conforme o trabalho de Reis (1999) citado anteriormente, podemos perceber uma política representacional presente nesses argumentos, comumente utiliza- dos em meio a disputas familiares. Esta política implica a construção de discursos identitários, baseados em normas essencialistas e ainda com apelo à noção de risco. Tal política também colabora para o efeito que destacamos em Cerruti (2007): a fixação do sujeito a um lugar discursivo que o aliena a este mesmo discurso de caráter adversarial.

\section{CONSIDERAÇÕES FINAIS}

A primeira consideração a ser feita é a da possibilidade de utilização do referencial de Schritzmeyer (2001) para a leitura social dos processos em Direito de Família. Da mesma forma que no Tribunal do Júri, as narrativas dos advogados se baseiam em estereótipos e utilizam um discurso de caráter dramáticosociológico. No caso do Direito de Família, poderíamos acrescentar o caráter psicológico, em uma relação direta com a noção de pessoa em desenvolvimento.

Para ratificar o interesse desta pesquisa, devemos registrar que não estamos analisando o valor dos argumentos utilizados, ou seja, reconhecemos a relevância de tais argumentos em muitos casos em que as decisões judiciais protegem os interesses das crianças e dos adolescentes envolvidos nos conflitos de família. Nosso interesse foi verificar e refletir sobre as imagens e identidades produzidas por discursos variados e vivificadas pelo discurso jurídico em meio ao jogo adversarial argumentativo.

Tais imagens foram constatadas e demonstram a forma como o discurso jurídico, fonte de poder, é agenciado por noções exteriores a este mesmo discurso. Noções que o discurso jurídico tende a legitimar em seus jogos e decisões e, assim, fortalecer no seio do discurso social.

Que outras condições e determinações estariam sendo negadas ou apagadas por um discurso que pretende ordenar as relações sociais construindo personagens com o foco no melodrama familiar? Será necessário, para atuar neste discurso, lidar somente com personagens moralizados, termo utilizado por Diniz (2001), e não considerar o componente trágico das histórias familiares? Estaríamos querendo eliminar este componente para lidar somente com os supostamente necessários "finais felizes"?

Este jogo, da forma como se estrutura, pode estar contribuindo para a manutenção de litígios na medida em que estimula a utilização de argumentos não fun- 
damentados e que podem ferir afetivamente os adversários, além de dificultar uma decisão judicial que possa considerar de forma crítica o paradigma atual do melhor interesse da criança. $\mathrm{O}$ resultado desta pesquisa pode contribuir com a reflexão dos operadores do direito sobre as bases discursivas que sustentam o jogo jurídico, bases que, em Direito de Família, podem contribuir muitas vezes para o incremento do sofrimento experimentado pelos familiares nos processos judiciais neste campo.

A prática da intervenção nos casos judiciais, rotina para a equipe técnica da instituição pesquisada, e a prática da mediação, ainda em gestação, têm sido estratégias na tentativa de contribuir na direção da possibilidade de desconstruir tais personagens estabelecidos em função, muitas vezes, dos próprios ritos jurídicos. Isso sinaliza a possibilidade da resolução de conflitos familiares de maneira menos sofrida para os envolvidos.

Por fim, registramos novamente a importância de se manter aberta a possibilidade de novas pesquisas que contribuam de formas distintas para a interface da família com o direito, revelando outras categorias e relações de análise. Somente desta forma, poderemos refletir e propor práticas que mantenham o questionamento sobre o processo de normatização familiar.

\section{REFERÊNCIAS}

Balandier, G. (1982). O poder em cena. (L.T.C. Moura, Trans.). Brasília: Editora UnB.

Cerruti, M. Q. (2007). Bate-se em uma mulher: Impasses da vitimização (Dissertação de Mestrado). Universidade de São Paulo, São Paulo.

Diniz, D. (2001). Antropologia e os limites dos direitos humanos: o dilema moral de Tashi. In Novaes, R.R. \& Kant de Lima, R. (orgs.) Antropologia e Direitos Humanos (pp. 17-46). Niterói: EdUFF.

Donzelot, J. (1980). A polícia das famílias. (M.T. da C. Albuquerque, Trans.). Rio de Janeiro: Graal.

Fonseca, M.F. (2002). Michel Foucault e o direito. São Paulo: Max Limonade.

Foucault, M. (1992). Microfísica do poder. (R. Machado, Trans.). Rio de Janeiro: Graal.
Foucault, M. (1996). A verdade e as formas jurídicas. (R.C. de M. Machado \& E. J. Morais, Trans.). Rio de Janeiro: Nau.

Foucault, M. (2008). A arqueologia do saber. (L. F. B. Neves, Trans.). ( $7^{a}$ ed.). Rio de Janeiro: Forense Universitária, 1987.

Huizinga, J. (2000). Homo ludens. O jogo como elemento da cultura. (J.P. Monteiro, Trans.). (4 ${ }^{\mathrm{a}}$ ed.). São Paulo: Perspectiva.

Miranda Jr. H.C. (1999). A pessoa em desenvolvimento. $O$ sujeito de direito e o discurso psicológico nas leis brasileiras para a infância e juventude (1927, 1979 e 1990) (Dissertação de Mestrado) Universidade Federal de Minas Gerais, Belo Horizonte.

Moreira, L. E. \& Toneli, M. J. F. (2014). Paternidade, família e criminalidade: Uma arqueologia entre o direito e a psicologia. Psicologia \& Sociedade 26, 36-46.

Reis, E. F. (2009). Varas de Família. Um encontro entre psicologia e direito. Curitiba: Juruá.

Rodrigues, M.C., Couto, E.M. \& Hungria, M.C.L. (2005). A influência dos laudos psicológicos nas decisões judiciais das Varas de Família e Sucessões do Fórum Central da capital de São Paulo. In: S. Shine (orgs.). Avaliação psicológica e lei: Adoção, vitimização, separação conjugal, dano psicológico e outros temas (pp.19-36). São Paulo: Casa do Psicólogo.

Schritzmeyer, A. L. P. (2001). Controlando o poder de matar: uma leitura antropológica do Tribunal do Júri ritual lúdico e teatralizado (Tese de doutorado) Universidade de São Paulo, São Paulo.

Shine, S. (2002). O conflito familiar transformado em litígio processual. In: Agostinho, M. L. \& Sanchez, T. M. (orgs.). Família: Conflitos, reflexões e intervenções (pp. 63-74). São Paulo: Casa do Psicólogo.

Theodoro Júnior, H. (2005). Curso de direito processual civil volume 1. Rio de Janeiro: Forense.

Recebido em: 20/02/2014 Primeira decisão editorial em: 15/07/2014 Aceito em: 30/10/2014 